\title{
Musculoskeletal Pain and Mental Agony Reacting to Ergonomic Risks in the Thai Informal Working Environment ${ }^{*}$
}

\author{
Jiraporn Tangkittipaporn \\ Chiang Mai University, \\ Chiang Mai, Thailand
}

\author{
Worapun Jiangsathaporn \\ Fareast Innovative R\&D Co., Ltd., \\ Amphur Bandbaotong, Thailand
}

\begin{abstract}
Objectives: The study aims to focus on the ergonomic risks on mental agony and musculoskeletal pain (MSP) as well as discuss the potential solutions for minimizing the negative consequences of occupational risks among Thai informal workers. Methods: The analysis sample comprised of 805 informal workers in Thailand. Research instruments were consisted of an interview questionnaire and the ergonomic checklist. Results: MSP location was highest distributed to upper back (86.8\%). Only $11.2 \%$ and $2.9 \%$ of the participants had no sign of anxiety and burnout. Poor work methods were identified as the most frequently exposed ergonomic risk. Burnout, anxiety, and workstation design were the significant risks impacting the severity of MSP. Physical environmental was the significant risk for anxiety, while physical environment and work methods were the significant risks for burnout. Conclusions: Interdisciplinary assessments and multi-level/sector approaches should be taken into account in planning the community health services for preventing occupational risks and MSP.
\end{abstract}

Keywords: Ergonomics, informal workers, mental agony, musculoskeletal pain (MSP), risk factors, descriptive survey study

\section{Introduction}

Thailand is a developing country and the informal sector has become a growing source of employment for large numbers of youth and also for elders staying at homes. The informal sector accounted for more than $64 \%$ of the Thai total workforce (Fernquest, 2015). Among 24.1 million informal workers, the biggest number of informal workers (41.9\%) was distributed to the northeast region, followed by the north region (21.5\%) and the south region (12.8\%) (National Statistical Office, 2009).

The majority of the informal workers live in the rural area which lacks the welfare services. Their homes and workstation are one and the same places. They share the common characteristics, viz., working in an informal unorganized atmosphere, without a formal job contract, received incomes are not proper or inadequate to cover the household expenses, no employment insurance, and individualistic. They are normally not under legalization and are usually unprotected by the social security system (Kaewboonchoo, Kongtip, \&

\footnotetext{
*Acknowledgements: The research was supported by TRF, Thailand.

This research paper was presented at 2nd Annual Experts Meeting on Neurocognitive Disorders \& Stress Management, Nov 7-8, 2016, Barcelona, Spain.

Jiraporn Tangkittipaporn, Ph.D., associate professor, Department of Psychology, Faculty of Humanities, Chiang Mai University, Tel: 66-814444393; E-mail: tangkitt@hotmail.com, jiraporn.t@cmu.ac.th.

Worapun Jiangsathaporn, M.S., Researcher, Fareast Innovative R\&D Co., Ltd. 75/44 Mu 5, Tambol Banglugpatana, Amphur Bandbaotong, Nonthaburee Province 11110, Thailand. Tel: 66-816393299; E-mail: w.jiangsataporn@gmail.com.
} 
Woskie, 2015; Thanachaisethavut, 2011). They receive no training or supervision due to their unemployment contact. Therefore, they are not aware and neither concerned about the occupational risks and the impacts (Kongtip et al., 2015).

The economic pressure (Gangopadhyaya, Chakrabarty, Sarkar, Dev, \& Das, 2014), social disadvantages (Chaman et al., 2015) and disorganized workstations (Shah \& Vyas, 2015) expose the informal workers to an array of occupational risks including ergonomic risks and mental risks as well as musculoskeletal system diseases (Bernardino \& Andrade, 2015; Tangkittipaporn \& Tangkittipaporn, 2006). Various literature and research have supported that poor ergonomically workstation design (Pandit, Kumar, \& Chakrabarti, 2013), constrained work methods and movements (Gangopadhyay \& Dev, 2014) do not only increase physical tension and biomechanical load but also enhance mental agony (Harvey et al., 2014) including anxiety, depression (Roizenblatt et al., 2015), and burnout (Gholami et al., 2016) which finally develop musculoskeletal pain (MSP) (Aghilinejad, Sadeghi, Abdullah, Sarebanha, \& Bahrami-Ahmadi, 2014; Hanklang, Kaewboonchoo, Silpasuwan, \& Mungarndee, 2014). On the other hand, individuals with MSP are exposed to an increased risk for mood alterations and can also result in reduced activity, deterioration of work performance (Khan \& Pope-Ford, 2015) and unwanted errors and accidents in the workplace (Bair et al., 2013; Tsarali et al., 2014). Further, the combined effects of MSP and mental agony are the most frequent causes of physical sickness such as chronic fatigue, sleep disturbance, chronic headache, impaired attention, and poor memory, etc. (Aytekin et al., 2015; Thinkhamrop \& Laohasiriwong, 2015). All of these malaises represent a potentially huge cost in terms of human distress and economic burden for the individual and society (Oh, Yoon, Seo, Kim, \& Kim, 2011).

The combined effects of ergonomic risks on workers' MSP have been studied extensively in the west. However, up to this modern period, there have been no systematic studies of the impacts of ergonomic risks on mental agony and MSP among the informal workers, specifically in Chiang Mai and Lumphun, which are the northern provinces of Thailand. The lack of research in this field may present one major barrier in preventing Thai informal workers from developing awareness and controlling emerging risks and their impacts. The objectives of this paper are to explore the prevalence and the association among ergonomic risks, mental agony, and MSP. The outcomes of the study may help to provide potential solutions and recommended practices for minimizing the negative ergonomic, psychological and musculoskeletal consequences of the Thai informal employment.

\section{Theoretical Framework}

Informal workers are workers with informal job status. They are normally not legalization and unprotected by social security system (Thanachaisethavut, 2011). Based on the concept of National Statistical Office (NSO, 2011), the Thai informal workers can be classified into three groups: (1) Agricultural informal workers are small-scale farmers; contract farmers and workers hired for agricultural activities, such as planting, fishing, forestry, cattle farming, salt farming; (2) Service informal workers are independent or self-employed workers or non-professional service providers, such as garbage collectors/waste pickers, street vendors, drivers; (3) Manufacturing informal workers/home-based handicraft workers are workers in very small-scale or causal self-employment or subcontracted activities including wood crafts, textile and garment, leather crafts, plastic flower craft, mulberry paper crafts, agri-food, silver crafts, ceramics and pottery, bamboo crafts, souvenir and painting crafts. According to the 2010 NSO's survey, most of the informal workers were engaged in agricultural sector (60\%), followed by service sector (31.4\%), and manufacturing sector (8.6\%). 
Home-based handicraft workers are manufacturing informal workers. Handicrafts are one of the most valuable goods produced mostly in rural areas of Thailand and are indeed added values to the Thai socio-economy. However, the majority of home-based handicraft workers live in rural which lack of welfare services. Their homes and workplaces are one and the same places which are unhealthy environment and unsafe work conditions (Lehtinen, 2012). The handicraft workers under informal sector share the common characteristics, viz., making craft by hand skills, long hours of static posture without adequate breaks, repetitive work methods and conditions, irregular work schedules, prolonged work hours, no work-no pay system. Most of the crafts take place in narrow-spaced indoor where the workers are constrained to work under high humidity, dusty and foul-smelling, insufficient light and poor air circulation. The others take place outdoors, where workers are exposed to heat stress problems (Yoopat, Toicharoen, \& Glinsukon, 2002). The ill design of workstation and the nature of works may constrain the workers to sit or stand and hold objects in static postures, making craft by repetitive, monotonous pattern and prolong repetitive movements (Sungkhabut \& Chaiklieng, 2011; Pandit et al., 2013). The shortage of income and low education (Gangopadhyaya et al., 2014; Lehtinen, 2012) confine them to be unable to access necessity technologies and unaware of the significant impacts of poor ergonomically sound workstation and unsafe working practices (Shah \& Vyas, 2015) which are the main known risk factors of MSP (Gangopadhyay \& Dev, 2014). Furthermore, they have to handling their household tasks apart from the craft works (Chaman et al., 2015). A combination of poor socioeconomic aspects, high psychosocial demands and financial crisis, unhealthy working environment, unsafe working practices, therefore, enhance their mental agony (Harvey et al., 2014) and makes them become helpless in avoiding MSP (Hanklang et al., 2014).

Ergonomic risks are the aspects of workstation or actions that impose a biomechanical stress on the workers' musculoskeletal system (Jaffar, Abdul-Tharim, Mohd-Kamar, \& Lop, 2011). Ergonomic risk factors arise from worker's (1) improper and insufficient workstation design such as inadequate chair, height and space of working area, unorganized materials system, poor management of space and hygiene for garbage and wash room); (2) unsafe work methods such as manual operation, awkward postures, prolong working hours, repetitive movement; (3) poor physical environment such as excessive heat, dim, noisy, humidity, dusty and smelling of working areas; and (4) inefficient and inappropriate technology such as tools/equipment require excessive physical demands, handling loads, repetitive movements or vibration.

Musculoskelatal pain (MSP) is defined as discomfort or numbness or pain experienced in soft tissue of the different body regions including neck, shoulders, upper back, upper arms, abdomen, lower arm, finger, lower back, buttock, finger, thighs/knees, legs/feet. MSP is regarded as a major health problem and it is the most prevalence illness among informal or unorganized sectors workers (Gangopadhyay \& Dev, 2014). It is the manifestation of physical ergonomic risks (Awan, Nasrulla, \& Cummings, 2010) and mental agony (Bonzini, Bertu’, Veronesi, Conti, Coggon, \& Ferrario, 2015; Gholami et al., 2016; Poleshuck et al., 2009), and is the leading causes of work disability (Alghadir \& Anwer, 2015), lost productivity, immoderate of productive time (Stewart, Ricci, Chee, Morganstein, \& Lipton, 2003), sickness absence (Choobineh, Hosseini, Lahmi, Jazani, \& Shahnavaz, 2007), huge social security costs, individual quality of life and national economic growth (Oh et al., 2011).

Mental agony also known as mental suffering or mental pain is defined as intense feelings of suffering which includes feelings of anxiety and burnout symptoms: (1) Anxiety refers to distress feeling mainly consisting of fear and worry about a future which seems uncertain and threatening. It is most commonly triggered by unpleasant and uncontrollable negative thoughts and images about uncertain events that may have one or more negative consequences (Dugas, Gagnon, Ladouceur, \& Freeston, 1998); and (2) Burnout refers to a 
state of mental, emotional and physical exhaustion resulting from the imbalance between situational supply and the individual's expectation (Pines \& Aronson, 1981). Maslach, Schaufeli, and Leiter (2001) identified burnout as a psychological state resulting from prolonged emotional or psychological stress of job. It manifests itself as emotional exhaustion, depersonalization, and professional completion. Emotional exhaustion is a feeling of extreme energy loss and a sense of being completely drained out of emotional and physical strength. Depersonalization is a negative attitude and reaction to colleague and earning. Professional completion is a development of feeling of unhappy about oneself and dissatisfied with job accomplishment. Armon, Melamed, Shirom, and Shapira (2010) and Gholami et al. (2016) supported that burnout represents accumulated exposure to work-related stresses. Anxiety is a common mental problem which is often resulted in burnout burdens. Prolong burnout lead to loss of physical and psychological energy.

MSP and mental agony are influenced by the consequences of poor socioeconomic aspects (Maslach et al., 2010), manual dexterity job and poor ergonomically work atmosphere (Harnois \& Gabriel, 2000; Gangopadhyay \& Dev, 2014) such as, overwork, prolong poor posture, lack of clear instructions and supports, unrealistic deadlines and pays, lack of decision-making, job insecurity, isolated working conditions, surveillance, and inadequate physical environment and technology (LaMontagne, Keegel, \& Vallance, 2007). Informal workers are employing in a less favorable social, environment and economic position tend to exposure and vulnerability to the risks of anxiety and stress (Bernardino \& Andrade, 2015). These conditions may be related with an exhausting type of work that requires excessive physical effort and psychological morbidities which contributes to the development of burnout. Mental agony is stimulated when the body does not adjust to some inappropriate work environment. Feeling that the work is undervalued may also convince workers to suffer psychological anxiety and stress. The long term anxiety and stress reactions may result in burnout, chronic fatigue and poor performance. Research indicates that mental agony and other work-related psychosocial hazards are emerging as the leading contributors to the burden of occupational disease and injury. Mental agony may influence workers' capacity to cope with their work demands and their motivation to act appropriately in managing risks at work. In addition, mental agony may increase muscle tension and decrease micropauses in muscle activity which finally stimulate the incidence of MSP (DeCroon, Sluiter, Kuijer, \& Frings-Dresen, 2005).

\section{Methodology}

\section{Unit of Analysis}

The sample unit was 979 households located in Chiangmai and Lumphun provinces, northern part of Thailand.

\section{Sample and Sampling Techniques}

To ensure that the sample in this study is adequate for regression analysis, The study applies the formula from Green (1991) who suggested that the sample size ( $n$ ) should be greater than $104+m$ (where $m$ is the number of independent variables) for testing individual predictors (Chong, Ooi, Lin, \& Tang, 2009). As a result, the sample size of the study should not less than 122 .

The study sample was drawn through a purposive and snowball sampling techniques to obtain 979 informal workers based on 3 criteria: (1) working at home; (2) making craft by hand; and (3) household located in Chiang Mai or Lumphun provinces, which are the northern part of Thailand. 174 workers gave incomplete 
responses resulting in a final response rate of $82.23 \%$. The analysis sample comprised of 805 workers including ten groups of handicraft profession: wood crafts, textile and garment, leather crafts, plastic flower crafts, mulberry paper crafts, agri-food, silver crafts, ceramics and pottery, bamboo crafts, souvenir and painting (Table 1 describes the sample characteristics).

\section{Research Instruments and Quality Testing}

Data were obtained in individual household. An interview questionnaire and the ergonomic checklist were developed in a Thai version specifically for this study and collect required data by trained field workers. The interview questionnaire covered basal variable scale, mental agony scale and MSP scale: (1) The basal variable scale includes questions such as age, gender, education, and various employment experiences; (2) The mental agony scale comprised 2 components of anxiety (20 items) and burnout (25 items). Each of the items was scored using a four-point scale from 0 ("Never") to 3 ("Very often"); and (3) The scale of MSP was measured pain or discomfort or numbness in different body regions during the preceding year including neck, shoulders, upper back, upper arms, abdomen, lower arm, lower back, buttock, finger, thighs/knees, legs/feet. Each of the complaint was scored using a four-point scale from 0 ("Never") to three ("Very often"). The ergonomic checklist was consisted of 4 parts of ergonomic risk factors including workstation design 12 items, work methods 25 items, physical environment 9 items, and technology 20 items. Each of the items was scored using a two point scale from 0 (“No") to 1 ("Yes"). Taking mean as a cut point, each of the variables was classified to three levels, i.e., no sign (mean $=0$ ), mild level (lower than mean), and severe level (higher than mean).

After the content validity of the research instruments were checked by three experts, the reliability test was established through a pilot study in Hangdong, Chiang Mai province. A total of 30 wood craft workers participated in the study. Internal reliability was examined by Cronbach Alpha coefficients. The results showed that the ergonomic checklist's reliability coefficients ranged from 0.662 to 0.806 . The mental agony scales' reliability coefficients ranged from 0.924 to 0.925 . While the reliability score of the MSP scale was 0.884 (Nunnally, 1978; Paige \& Littrell, 2002). The results of validity testing show that discriminative indices ranged from 34.331 to 41.663 (The statistical significance for all tests was a 0.001 level of confidence).

The final reliable versions of the instrument were evaluated again by the ethics committee of the TRF in Bangkok.

\section{Results}

\section{Participants' Personal Background}

Of the total 805 home-based handicraft workers, 67\% were women, age ranged from 13 to 78 years ( $\bar{x}=$ 37.34). Approximately 57.5\% of the participants had attained basic education and 3\% did not have any formal education. In the area of employment, it was found that the average working time was 7.19 hours/day, average working day was 5.87 days/week, average work tenure was 7.79 years and average income was 4122.72 baht/month.

\section{Prevalence of MSP, Mental Agony and Ergonomic Risks}

As shown in Figure 1, pain location was highest distributed to upper back, followed by upper arms, shoulders, neck, thighs/knees, lower arms, buttocks, fingers, lower back, legs/feet, and abdomen, respectively.

When considering the levels of MSPs in Table 1, it was found that only 3.5\% of the participants had no sign, 54.3\% had mild level of MSP, whereas 42.2\% met the criteria of severe MSP. The prevalence of mental 
agony was found to be a highest prevalence in burnout (mild $=55.8 \%$, sever $=41.4 \%$ ), followed by anxiety (mild $=45.6 \%$, sever $=43.2 \%)$. Regarding ergonomic risks, poor work methods was identified as the most frequently exposed risk (mild $=50.1 \%$, severe $=49.9 \%$ ), followed by insufficiency and inappropriate technology (mild $=43.5 \%$, severe $=53.7 \%)$, unhealthy physical environment $($ mild $=43.0 \%$, severe $=41.5 \%$ ), and poor workplace design (mild $=26.1 \%$, severe $=45.3 \%$ ) respectively .

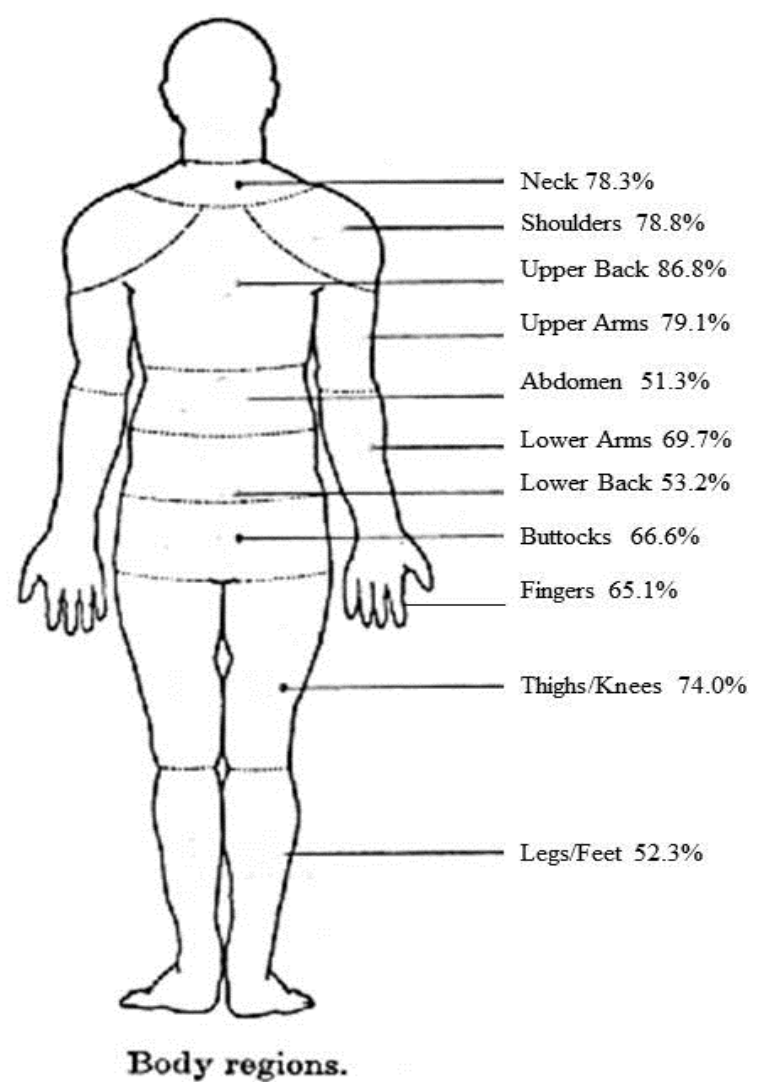

Figure 1. Prevalence of MSP in various parts of the body.

Table 1

Prevalence of MSP, Ergonomic Risks and Mental Agony during the Preceding Year of all Participants

\begin{tabular}{lcc}
\hline Variables & $n(\%)$ & $\bar{x}(S D)$ \\
\hline Musculoskeletal pain (score, range 0-3) & $28(3.5)$ & \\
\hline No sign & $437(54.3)$ & \\
$\quad$ Mild & $340(42.2)$ & \\
$\quad$ Severe & & $0.58(0.46)$ \\
\hline Mental risks & & \\
\hline (1) Anxiety (range 0-3) & $90(11.2)$ & \\
$\quad$ No risk & $367(45.6)$ & $0.60(0.43)$ \\
$\quad$ Mild & $348(43.2)$ & \\
$\quad$ Severe & & \\
(2) Burnout (range 0-3) & $23(2.9)$ & \\
$\quad$ No risk & $449(55.8)$ & \\
$\quad$ Mild & $333(41.4)$ & \\
$\quad$ Severe & & \\
\hline
\end{tabular}


Table 1 continued

\begin{tabular}{lcc}
\hline Variables & $n(\%)$ & $\bar{x}(S D)$ \\
\hline Ergonomic risks & & $0.22(0.23)$ \\
\hline (1) Workstation design (range 0-1) & $230(28.6)$ & \\
$\quad$ No risk & $210(26.1)$ & $0.39(0.15)$ \\
$\quad$ Mild & $365(45.3)$ & \\
$\quad$ Severe & $0(0.0)$ & \\
(2) Work Methods (range 0.04-0.84) & $403(50.1)$ & $0.27(0.22)$ \\
$\quad$ No risk & $402(49.9)$ & \\
$\quad$ Mild & & \\
$\quad$ Severe & $125(15.5)$ & $0.36(0.16)$ \\
(3) Physical Environment (range 0-0.89) & $346(43.0)$ & \\
$\quad$ No risk & $334(41.5)$ & \\
Mild & & \\
Severe & $23(2.9)$ & \\
(4) Technology (range 0-0.8) & $350(43.5)$ & \\
No risk & $432(53.7)$ & \\
Mild & & \\
Severe &
\end{tabular}

\section{Factors Impacting Mental Agony and MSP Severity}

Before executed the multiple regression analysis for testing the hypotheses, the values of tolerance and the variance inflation factor (VIF) were checked. Data presented in Table 2, 3 shows that the values of tolerance were exceed 0.10 and VIF were less than 10 indicating no multi collinearity problem (Everitt, 2010).

Table 2 displays the results from standard regression models, testing the impacts of ergonomic risks (design, methods, environment, technology) and mental agony (anxiety, burnout) on MSP.

Table 2

Regression Results of Ergonomic Risks and Mental Agony Impacting MSP Severity

\begin{tabular}{|c|c|c|c|c|c|}
\hline \multirow{2}{*}{$\begin{array}{l}\text { Risk } \\
\text { factors }\end{array}$} & \multirow{2}{*}{$\begin{array}{l}\text { Standardized } \\
\text { coefficients } \\
(\beta)\end{array}$} & \multirow[t]{2}{*}{$t$} & \multirow[t]{2}{*}{ Sig. } & \multicolumn{2}{|c|}{$\begin{array}{c}\text { Collinearity } \\
\text { statistics }\end{array}$} \\
\hline & & & & Tolerance & VIF \\
\hline Con. & & 9.029 & 0.000 & & \\
\hline Burnout & 0.285 & 6.001 & 0.000 & 0.467 & 2.139 \\
\hline Anxiety & 0.125 & 2.622 & 0.009 & 0.465 & 2.151 \\
\hline Design & 0.071 & 2.029 & 0.043 & 0.868 & 1.152 \\
\hline Environment & -0.058 & -1.486 & 0.138 & 0.690 & 1.449 \\
\hline Methods & 0.045 & 1.176 & 0.240 & 0.720 & 1.388 \\
\hline Technology & 0.030 & 0.818 & 0.413 & 0.772 & 1.295 \\
\hline
\end{tabular}

Note. $R$-square $=0.157 ; F=24.768, p=0.001$.

(1) Mental risks had more profound impacts on MSP severity compared to ergonomic risks. The standard model explained $15.7 \%$ of the variance in MSP severity.

(2) Among the two components of mental agony, burnout $(\beta=0.285, t=6.001, p<0.001)$ had stronger impact on MSP severity than anxiety $(\beta=0.125, t=6.622, p<0.01)$.

(3) Among the four components of ergonomic risks, only workstation design $(\beta=0.71, t=2.029, p<0.05)$ had significant impact on MSP severity. 
Table 3

Regression Results of Ergonomic Risks Impacting Mental Agony

\begin{tabular}{lllllllll}
\hline Risk & \multicolumn{9}{c}{ Anxiety } \\
\cline { 2 - 9 } Factors & $\beta$ & $t$ & Tolerance & VIF & $\beta$ & $t$ & Tolerance & VIF \\
\hline Con. & 8.707 & & & & 8.331 & & & \\
Design & 0.071 & 1.926 & 0.872 & 1.146 & 0.035 & 0.945 & 0.872 & 1.146 \\
Environment & 0.203 & $4.970^{* * *}$ & 0.712 & 1.405 & 0.131 & $3.196^{* * *}$ & 0.712 & 1.405 \\
Methods & 0.016 & 0.406 & 0.727 & 1.375 & 0.090 & $2.221^{*}$ & 0.727 & 1.375 \\
Technology & 0.037 & 0.940 & 0.774 & 1.292 & 0.047 & 1.189 & 0.774 & 1.292 \\
$R$-square & 0.049 & & & & 0.44 & & & \\
$F$-test & $10.323^{* * *}$ & & & & $9.124^{* * *}$ & & & \\
\hline
\end{tabular}

Table 3 shows that physical environmental risk had significant impacts on anxiety ( $\beta=0.203, t=4.970, p$ $<0.001)$ severity whilephysical environmental risk $(\beta=0.131, t=3.196, p<0.001)$ and work methods $(\beta=$ $0.131, t=3.196, p<0.001$ ) had significant impacts on burnout severity.

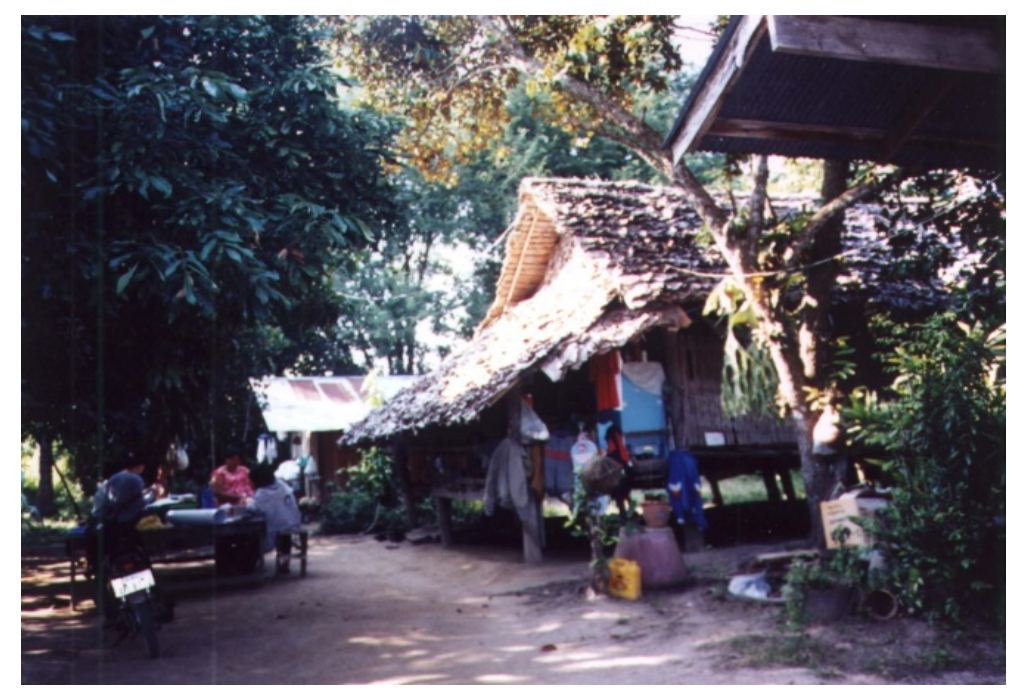

Figure 2. Workers worked in the unorganized environment and poor workstation design.

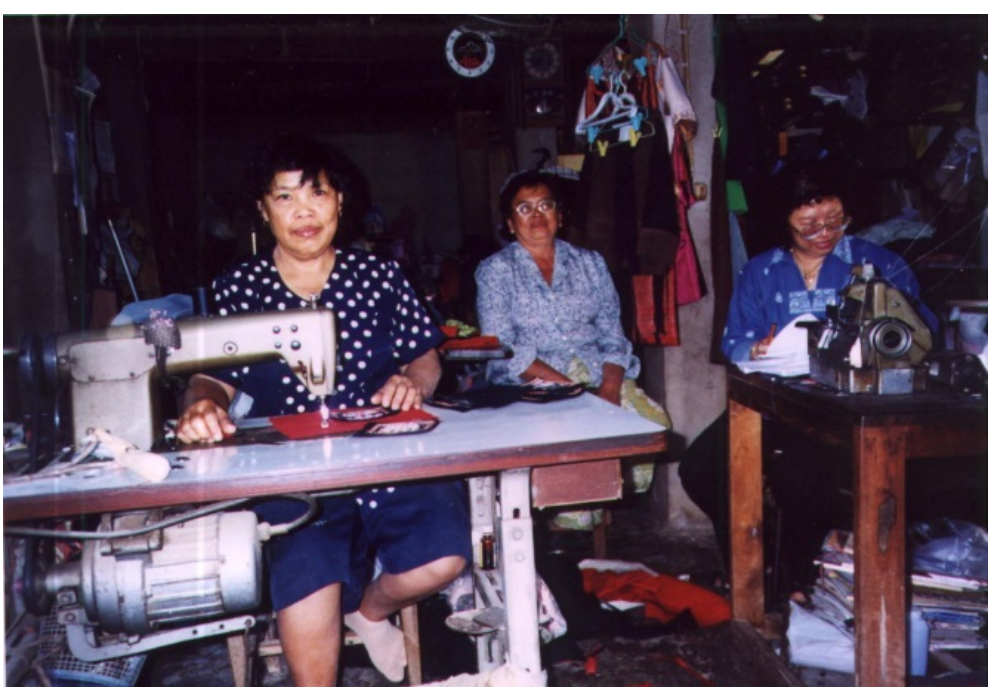

Figure 3. Workers worked in the insufficient light and air circulation environment. 


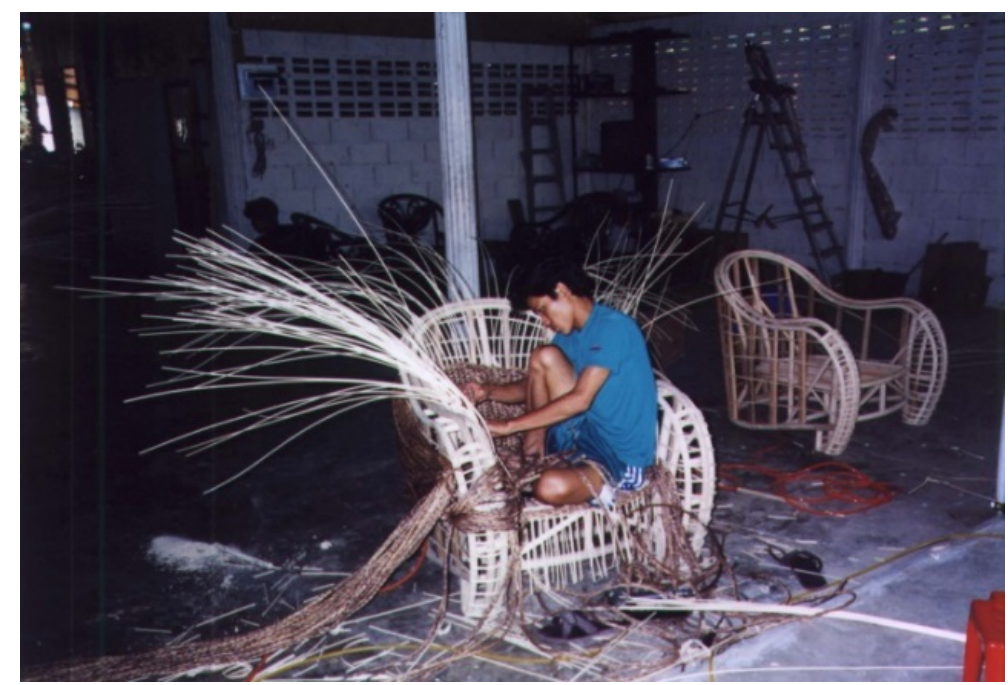

Figure 4. Workers worked in a narrow and lack of clearance space.

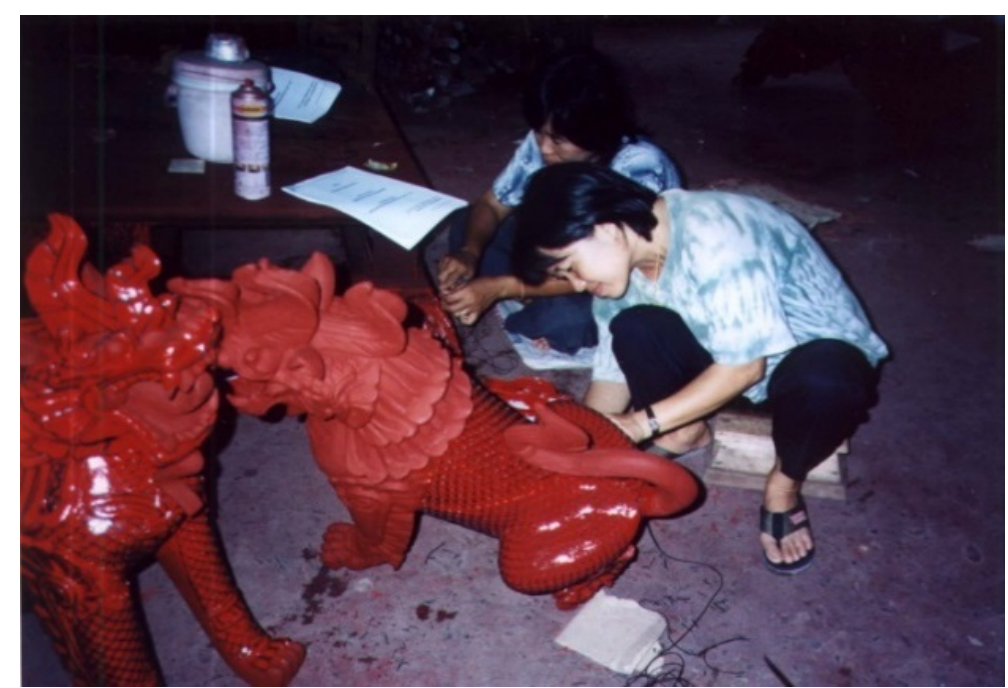

Figure 5. Workers worked for long hours in static positions.

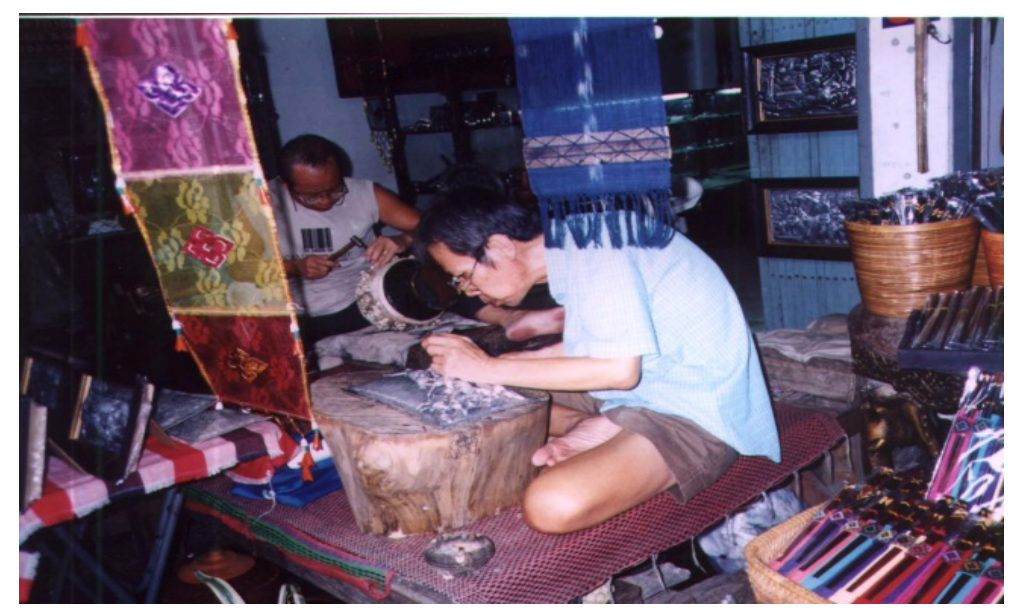

Figure 6. Workers had to bend down the head and holding the arms aloft. 


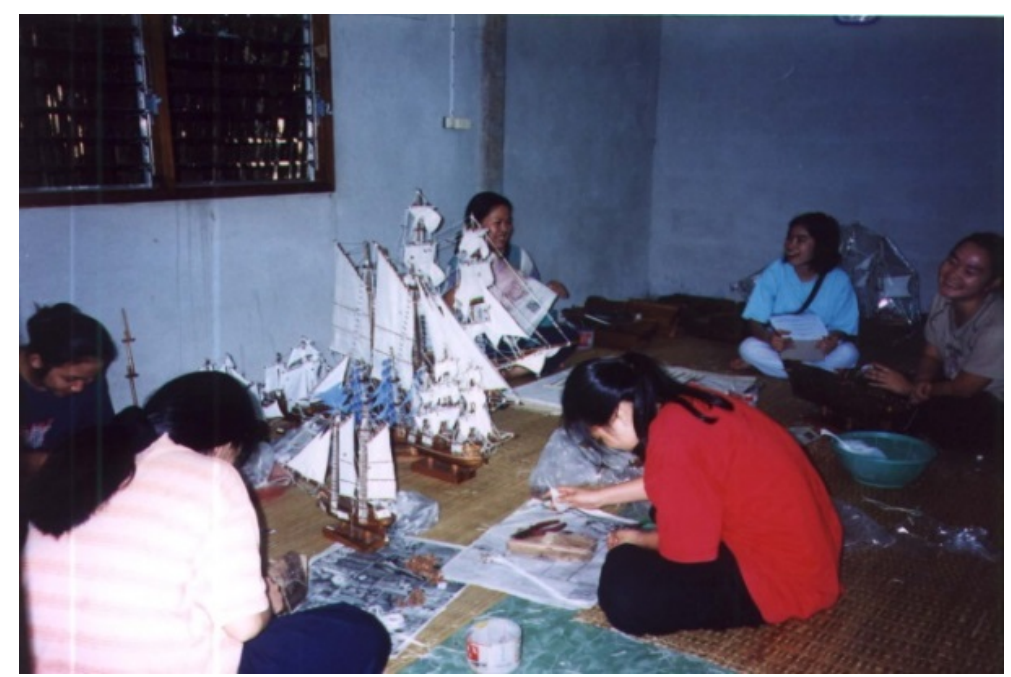

Figure 7. Workers seated on the floor without back support.

\section{Conclusion/Discussions}

The findings of the study through a subjective assessment of body pain discovered that most of the Thai informal workers experienced MSP. Upper back pain was the commonest location to be experienced by the Thai informal workers. Burnout was the highest prevalence for mental agony and poor work methods was identified as the most frequently exposed ergonomic risk. Burnout, anxiety and work station design were the significant risk factors impacting MSP severity. Physical environment and work methods were the significant risk factors for burnout.

Home-based handicrafts works are manual jobs requiring long hours of static work, irregular work schedule, no work no pay system, and lack of additional allowances or professional support. They are individualistic and are generally provided by an informal unorganized work environment and poor workstation design. The shortage of income and low education may be the main cause resulting in poor workstation design and unsafe working methods (Shah \& Vyas, 2015).

Improper design of the workstations, e.g., unsuitable working chairs, humid, dusty and foul-smelling working areas, inadequate height, excessive heat, narrow and lack of clearance space, insufficient light and air circulation, poor housekeeping, unorganized materials and inappropriate equipments, exposure to hazardous chemicals and dusts, may have developed poor work methods and awkward posture (Hanklang et al., 2014; Lehtinen, 2012) (see Figures 2-4).

Furthermore, the nature of craft works and the informal workers' unsafe working practices may constrain the workers to perform in awkward postures (Gangopadhyay \& Dev, 2014), forceful manual exertions, holding the arms aloft, pulling or pushing (Falcao et al., 2015), repetitive operation (Pandit et al., 2013), mechanical pressure concentrations, vibration, long working hours in static positions (Kongtiam \& Duangsong, 2010; Shah \& Vyas, 2015), prolong sitting or standing in an unnatural posture, working with hands at or above shoulder level, flexion of the neck, static contractions of upper back, and monotonous or repetitive work with upper arms. These poor work methods are the most prevailing risk posture resulting in the development of upper back pain (see Figures 5-7).

Considering the education level, the study suggested that, $3 \%$, and $85.3 \%$ of the Thai informal workers were respectively illiterate and received either primary or secondary school certificates. Their average earning 
was 8624.99 Baht/month. Low socioeconomic strata may limit the informal workers' awareness and ability to develop safety working practices and access quality resources to design and construct an ergonomically sound workstation. Furthermore, they had to handle their household tasks apart from the craft works (Chaman et al., 2015). Consequently, dissatisfaction regarding earnings (Gangopadhyaya et al., 2014), pressure from long working hours, and unsupported psycho-social employment conditions may have pressured the Thai handicraft workers to be under emotional anxiety, stress (Aghilinejad et al., 2014), and burnout (Gholami et al., 2016). These working atmospheres do not only attack them mentally but also enhance their physical fatigue. Therefore, it is unavoidable to stimulate the onset of anxiety (Chaudhury, Mahmood, \& Valente, 2009), burnout (Aghilinejad et al., 2014) and MSP (Khan \& Pope-Ford, 2015; Roizenblatt et al., 2015).

Work related MSP is not only found to be the most prevalent illness among informal workers in Thailand, but also found in other developing countries like India, Iran, Brazil, China, Africa, etc. However, bodily location of pain is related to the types of occupation and working groups. Upper back pain was found to be the most common site (86.8\%) among the Thai home-based handicraft workers. This finding is consisted with the study of Naz, Kwatra, and Ojha (2015) who found that upper back pain (73.44\%) was commonly experienced by Indian weavers. However, the majority of previous studies found that lower back pain was the most prevalence among the informal workers. This concerning issue was found in a study with $99 \%$ of the Indian bamboo basket making workers (Parimalam, Balakamakshi, \& Ganguli, 2006), 57.7\% of the Thai construction-related workers (Hanklang et al., 2014), 63.81\% of the Iranian steel workers (Aghilinejad, Choobineh, Sadeghi, \& Nouri, 2012), 59\% of the Chinese miners (Yue, Xu, Li, \& Wang, 2014), 87.0\% of the Indian embroidery workers (Gangopadhyaya et al., 2014), 50\% of the Saudi Arabian construction workers (Alghadir \& Anwer, 2015), 80\% of the Indian gold smith workers (Devi \& Kiran, 2015). 93.44\% of the Indian jewelry manufacturing workers (Salve, 2015), 86\% of the Indian weavers (Pandit et al., 2013), and 89.3\% of the Nigerian drivers (Akinpelu, Oyewole, Odole, \& Olukoya, 2011). On the other hand, shoulder pain was found to be the major problem among the Thai weavers (87.0\%) (Chantaramanee, Taptagaporn, \& Piriyaprasarth, 2015) and among Brazilian fish industry workers (71.3\%) (Falcao et al., 2015). Meanwhile, Sungkhabut and Chaiklieng (2011) found wrist/hand was the most prevalence MSP in Thai hand-operated rebar bender (90.0\%).

Numerous studies have shown that having a mental agony is a possible risk factor for MSP (Bonzini et al., 2015; Gholami et al., 2016; Roizenblatt et al., 2015) which may be similar to the present study whereby the majority of MSP was the results of mental agony such as anxiety and burnout as well as ergonomic risks like workstation design. Further, the severity of anxiety and burnout were also influenced by ergonomic risks such as physical environment and work methods. The finding is somewhat consistent with the study of Silva De, Hewage, and Fonseka (2009) found that workstation ergonomics have more profound effect on burnout compared to personal background and job characteristic.

It is postulated that anxiety induced stress and prolong of stress facilitate burnout. In other words, burnout represents accumulated exposure to stresses (Armon et al., 2010). These may be supported by the notion of Thinkhamrop and Laohasiriwong (2015) in that anxiety and stress lead to sleep deprivation and loss of physical and psychological energy due to a sleep deprivation may result in the occurrence of burnout. On the other hand, unnatural working methods and postures may not only have resulted in fatigue in localized muscles and also enhanced workers' mentally burnout. That is, the way work methods is designed, organized and managed results in a variation of physical postures and mental stress and finally lead to serious deterioration of mental and 
physical health (European Agency for Safety and Health at Work, 2007). Handicraft works may constrain the workers to work in awkward postures (Gangopadhyay \& Dev, 2014), such as flexed sitting posture, forward stretching, upright and side bending, prolonged flexion of the spine posture, forceful manual exertions, holding the arms aloft (Falcao et al., 2015), repetitive operation (Pandit et al., 2013) and inappropriate working positions (Riabroi \& Chaiklieng, 2011). These postural discomforts originate excessive physical load and mental strain which consequently induce not only the incidence of MSP but also anxiety and burnout symptoms (Sungkhabut \& Chaiklieng, 2011).

Psychological research has linked anxiety and burnout to MSP in several ways: Individual mental agony may influence workers' capacity to cope with their work situations and their motivation to act appropriately in managing risks at work (Bonzini et al., 2015). Anxiety and burnout increases pain perception and decrease pain thresholds. In other words, workers with high anxiety and burnout may be more worried about their work and daily life events and may also have a lower tolerance for MSP and tend to experience the greatest pain severity with those having low anxiety and burnout (Lucchetti, Oliveira, Mercante, \& Peres, 2012). Furthermore, workers who mostly experienced anxiety and burnout will progressively lose their physical and psychological energy, and finally develop the incidences of MSP (Aghilinejad et al., 2014).

Based on biologic research, it has supported a role for the brain neurotransmitters, serotonin and norepinephrine, in the modulation of mental reactions. Changes in mood (anxiety and burnout) are associated with the changes in serotonin and norepinephrine concentration in the brain regions. The dysregulation in one or both of these neurotransmitters may dampen peripheral pain signals and finally contribute to the frequent presence of MSP symptoms (Marks et al., 2009; Tops et al., 2007). According to De Heer et al. (2014), anxiety and burnout facilitates the central modulation of the pain response in the areas of periaqueductal gray, amygdala, and hypothalamus. When deficits occur in these areas, modulation of signals from the body is disturbed, leading to a more severe experience of pain. Ergonomic risks lead to musculoskeletal tenderness and pain by increased mental and muscle tension, decrease micropauses in muscle activity, increased biomechanical load, modified pain perception, reduced capacity to adapt appropriately (Bonde et al., 2005; DeCroon et al., 2005).

\section{Policy Implications and Recommendations}

The study consequently recommends the following agendas:

(1) The identification and assessment of MSP, ergonomic risks and mental risks that are associated with the Thai informal workers need to be initiated and communicated from time to time. Early detection of occupational risks and MSP, at a stage when symptoms are mild, will be more easily treatable.

(2) Interventions addressing clinical treatment or support for reducing mental agony, specifically for anxiety alleviation, needed to develop and implement in the community health care center.

(3) Training in ergonomically work practices and changes in work habits for appropriated working methods should be promoted to the informal workers to avoid MSP.

(4) Interventions for training and sharing knowledge of designing a healthy home-based workstation to eliminate ergonomic risks and mental agony should be set up for the Thai informal workers.

(5) National occupational health service and safety standards as well as social welfare policy and legislation needed to be included for the Thai informal sector.

(6) The information of the development and application of new policy, legislation, interventions and technologies need to be shared through mass media at both the national and local levels. 
(7) Regional networks of government institutions, researchers and practitioners for the promotion and exchange of national strategies, good practices and research for reducing occupation risks and MSP specifically for the informal sector should be established.

(8) The most interesting questions needed for an adequate research paradigm are:

(8.1) Which factors are the most potential causes and the practical control solutions for mental agony? And

(8.2) How to improve the informal workers' workstation for an ergonomically sound environment to alleviate MSP?

\section{References}

Aghilinejad, M., Choobineh, A. R., Sadeghi, Z., \& Nouri, M. K. (2012). Prevalence of musculoskeletal disorders among Iranian steel workers. Iranian Red Crescent Medical Journal, 14, 198-203.

Aghilinejad, M., Sadeghi, Z., Abdullah, A., Sarebanha, S., \& Bahrami-Ahmadi, A. (2014). Role of occupational stress and burnout in prevalence of musculoskeletal disorders among embassy personnel of foreign countries. Iranian Red Crescent Medical Journal, 16, 1-6.

Akinpelu, A. O., Oyewole, O. O., Odole, A. C., \& Olukoya, R. O. (2011). Prevalence of musculoskeletal pain and health seeking behaviour among occupational drivers in Ibadan, Nigeria. African Journal of Biomedical Research, 14, 89-94.

Alghadir, A., \& Anwer, S. (2015). Prevalence of musculoskeletal pain in construction workers in Saudi Arabia. The Scientific World Journal, 2015, 1-5. doi: 10.1155/2015/529873.

Armon, G., Melamed, S., Shirom, A., \& Shapira, I. (2010). Elevated burnout predicts the onset of musculoskeletal pain among apparently healthy employees. Journal of Occupational Health Psychology, 15, 399-408.doi: 10.1037/a0020726.

Awan, S., Nasrulla, M., \& Cummings, K. J. (2010). Health hazards, injury problems, and workplace conditions of carpet-weaving children in three districts of Punjab, Pakistan. International Journal of Occupational and Environmental Health, 16, 115-121.

Aytekin, E., Demir, S. E., Komut, E. A., Okur, S. C., Burnaz, O., Caglar, N. S., \& Demiryontar, D. Y. (2015). Chronic widespread musculoskeletal pain in patients with obstructive sleep apnea syndrome and the relationship between sleep disorder and pain level, quality of life, and disability. Journal of Physical Therapy Science, 27, 2951-2954. doi: 10.1589/jpts.27.2951.

Bair, M. J., Poleshuck, E. L., Wu, J., Krebs, E. K., Damush, T. M., Tu, W., \& Kroenke, K. (2013). Anxiety but not social stressors predict 12-month depression and pain severity. Clinical Journal of Pain, 29, 95-101. doi: 10.1097/AJP.0b013e3182652ee9.

Bernardino, M., \& Andrade, M. (2015). Informal work and the implications for the workers' health: An integrative review. Journal of Nursing Referência, 4, 149-157.

Bonde, J., Mikkelsen, S., Andersen, J., Fallentin, N., Baelum, J., Svendsen, S., Thomsen, J., Frost, P., Kaergaard, A., \& And, T. (2005). Understanding work related musculoskeletal pain: Does repetitive work cause stress symptoms? Occupational and Environmental Medicine, 62, 41-48. doi: 10.1136/oem.2003.011296.

Bonzini, M., Bertu’, L., Veronesi, G., Conti, M., Coggon, D., \& Ferrario, M. M. (2015). Is musculoskeletal pain a consequence or a cause of occupational stress? A longitudinal study. International Archives of Occupational and Environmental Health, 88, 607-612. doi:10.1007/s00420-014-0982-1.

Chaman, R., Aliyari, R., Sadeghian, F., Shoaa, J. V., Masoudi, M., Zahedi, S., \& Bakhshi, M. A. (2015). Psychosocial factors and musculoskeletal pain among rural hand-woven carpet weavers in Iran. Safety and Healthat Work, 6, 120-127. doi: 10.1016/j.shaw.2015.01.001.

Chantaramanee, N., Taptagaporn, S., \& Piriyaprasarth, P. (2015). The assessment of occupational ergonomic risks of handloom weaving in northern Thailand. Thammasat International Journal of Science and Technology, 20, 30-37.

Chaudhury, H., Mahmood, A., \& Valente, M. (2009). The effect of environmental design on reducing nursing errors and increasing efficiency in acute care settings: A review and analysis of the literature. Environment and Behaviour, 41, 755-786. doi: 10.1177/0013916508330392.

Choobineh, A., Hosseini, M., Lahmi, M., Jazani, R. K., \& Shahnavaz, H. (2007). Musculoskeletal problems in Iranian hand-woven carpet industry: Guidelines for workstation design. Applied Ergonomics, 38, 617-624. doi:10.1016/j.apergo.2006.06.005

Chong, A. Y., Ooi, K., Lin, B., \& Tang, S. Y. (2009). Influence of interorganizational relationships on SMEs' e-business adoption. Journal of Internet Research, 19, 3, 313-331. 
De Heer, E. W., Gerrits, M. M. J. G., Beekman, A. T. F., Dekker, J., van Marwijk, H. W. J., de Waal, M. W. M., Spinhovan, P., Penninx, B. W. J. H., \& van der Feltz-Cornelis, C. M. (2014). The association of depression and anxiety with pain: A study from NESDA. PLOS ONE. Retrieved $\quad$ March $30, \quad 2016$ from http://journals.plos.org/plosone/article?id=10.1371/journal.pone.0106907

DeCroon, E. M., Sluiter, J. K., Kuijer, P. P. F. M., \& Frings-Dresen, M. H. W. (2005). The effect of office concepts on worker health and performance: A systematic review of the literature. Ergonomics, 48, 119-134. doi: 10.1080/00140130512331319409.

Devi, K., \& Kiran, U. V. (2015). Work related musculoskeletal disorder among workers in unorganized sector. International Journal of Technical Research and Applications, 3, 225-229.

Dugas, M. J., Gagnon, F., Ladouceur, R., \& Freeston, M. H. (1998). Generalized anxiety disorder: a preliminary test of a conceptual model. Behaviour Research and Therapy, 36, 215-26.

European Agency for Safety and Health at Work. (2007). Expert forecast on emerging psychosocial risks related to occupational safety and health. FACTS. Retrieved March 30, 2016 fromhttp://osha.europa.eu/en/publications/factsheets/74

Everitt, B. S. (2010). Multivariable modeling and multivariate analysis for the behavioural sciences. London: Taylor and Francis Group, LLC.

Falcao, I. R., Couto, M. C. B. M., Lima, V. M. C., Pena, P. G. L., Andrade, L. L., Muller, J. S., Alves, I. B., Viana, W. S., \& Rego, R. C. F. (2015). Prevalence of neck and upper limb musculoskeletal disorders in artisan fisherwomen/shellfish gatherers in Saubara, Bahia, Brazil. NCBI. Retrieved January 24, 2016 from www.scielosp.org/pdf/csc/v20n8/en_1413-8123-csc-20-08-2469.pdf

Fernquest, J. (2015). 5 factors push Thailand's unemployment rate ridiculously low. Bangkok Post. Retrieved February 23, 2016, from http://www.bangkokpost.com/learning/work/466226/why-thailand-unemployment-rate-is-ridiculously-low

Gangopadhyay, S., \& Dev, S. (2014). Design and evaluation of ergonomic interventions for the prevention of musculoskeletal disorders in India. Annals of Occupational and Environmental Medicine, 26, 1-6. doi: 10.1186/2052-4374-26-18. See comment in PubMed Commons below

Gangopadhyaya, S., Chakrabarty, S., Sarkar, K., Dev, S., \& Das, T. (2014). Evaluation of low back pain among female Chikan embroidery workers of west Bengal. Journal of Industrial Engineering and Management Innovation, 1, 2-12.

Gholami, T., Pahlavian, A. H., Akbarzadeh, M., Motamedzade, M., Moghadam, R. H., \& Jeihooni, A. K. (2016). Effects of nursing burnout syndrome on musculoskeletal disorders. International Journal of Musculoskeletal Pain Prevention, 1, 35-39. doi: 10.7508/ijmpp.2016.01.006.

Green, S. B. (1991). How many subjects does it take to do a regression analysis? Multivariate Behavioral Research, 26(3), 499-510.

Hanklang, S., Kaewboonchoo, O., Silpasuwan, P., \& Mungarndee, S. (2014). Musculoskeletal disorders among Thai women in construction-related work. Asia-Pacific Journal of Public Health, 26, 196-202. doi: 10.1177/1010539512466429.

Harnois, G., \& Gabriel, P. (2000). Mental health and work: Impact, issues and good practices. Joint publication of WHO and the International Labour Organization (ILO). Genva: Switzerland.

Harvey, S. B., Joyce, S., Tan, L., Johnson, A., Nguyen, H., Modini, M., \& Groth, M. (2014). Developing a mentally healthy workplace: A review of the literature. Retrieved November 11, 2015 from https://www.headsup.org.au/docs/default-source/resources/developing-a-mentally-healthy-workplace_final-november-2014.p df?sfvrsn=8

Jaffar, N., Abdul-Tharim, A. H., Mohd-Kamar, I. F., Lop, N. S. (2011). A literature review of ergonomics risk factors in construction industry. Procedia Engineering, 20, 89-97. doi:10.1016/j.proeng.2011.11.142.

Kaewboonchoo, O., Kongtip, P., \& Woskie, S. (2015). Occupational health and safety for agricultural workers in Thailand: Gaps and recommendations, with a focus on pesticide use. New Solutions: A Journal of Environmental and Occupational Health Policy, 16, 1-19.doi: 10.1177/1048291115569028.

Khan, M., \& Pope-Ford, R. (2015). Improving and modifying the design of workstations within a manufacturing environment. Procedia Manufacturing, 4927-4934. doi:10.1016/j.promfg.2015.07.631.doi:10.1016/j.promfg.2015.07.631doi:10.1016/j.promfg.2015.07.631

Kongtiam, W., \& Duangsong, R. (2010). The effectiveness of health education program by an application of self-efficacy theory and social support on behavioural modification for low back pain reducing among informal sector workers (fishing net workers) in Baan Thum Sub-district, Muang District, Khon Kaen Province. KKU Research Journal (Graduate Studies), 10 , 77-86. 
Kongtip, P., Nankongnab, N., Chaikittiporn, C., Laohaudomchok, W., Woskie, S., \& Slatin, C. (2015). Informal workers in Thailand: Occupational health and social security disparities. New Solutions: A Journal of Environmental and Occupational Health Policy, 25, 189-211. doi: 10.1177/1048291115586036.

LaMontagne, A. D., Keegel, T., \& Vallance, D. (2007). Protecting and promoting mental health in the workplace: Developing a systems approach to job stress. Health Promotion Journal of Australia, 18, 221-228.

Lehtinen, S. (2012). Small-scale enterprises and informal sector. African Newsletter on Occupational Health and Safety, 22, 32-34.

Lucchetti, P., Oliveira, A. B., Mercante, J. P. P., \& Peres, M. F. P. (2012). Anxiety and fear-avoidance in musculoskeletal pain. Current Pain and Headache Reports, 16, 399-406.doi: 10.1007/s11916-012-0286-7.

Marks, D. M., Shah, M. J., Patkar, A. A., Masand, P. S., Park, G., \& Pae, C. (2009). Serotonin-norepinephrine reuptake inhibitors for pain control: premise and promise. Current Neuropharmacology, 7, 331-336. doi: 10.2174/157015909790031201.

Maslach, C., Schaufeli, W. B., \& Leiter, M. P. (2001). Job burnout. Annual Review of Psychology, 52, 397-422. doi: 10.1146/annurev.psych.52.1.397

Muhammad, N., Shah, M., Ahmad, M., \& Alam, I. (2010). Mental disorders: A glance at its socio-economic pushing factors in Peshawar. AGRIS, 8(1), 49-53.

National Statistical Office. (2009). The summary of informal sector survey. Ministry of Information and Communication Technology. Retrieved December 10, 2015, from http://web.nso.go.th/

National Statistical Office. (2011). The informal employment survey 2010. Ministry of Information and Communication Technology. Retrieved April 19, 2016, from http://service.nso.go.th/nso/nsopublish/themes/files /workerOutRep53.pdf

Naz, H., Kwatra, S., \& Ojha, P. (2015). Prevalence of musculoskeletal disorders among handloom weavers of Uttarakhand: An ergonomic study. Journal of Applied and Natural Science, 7, 102-105.

Nunnaly, J. C. (1978). Psychometric theory. New York: McGraw-Hill Book Company.

Oh, I., Yoon, S., Seo, H., Kim, E., \& Kim, Y. (2011). The economic burden of musculoskeletal disease in Korea: A cross sectional study. BMC Musculoskeletal Disorders, 12, 1-9. doi:10.1186/1471-2474-12-157.

Paige, R. C., \& Littrell, M. A. (2002). Craft retailers' criteria for success and associated business strategies. Journal of Small Business Management, 40(4), 314-331.

Pandit, S., Kumar, P., \& Chakrabarti, D. (2013). Ergonomic problems prevalent in handloom units of north east India. International Journal of Scientific and Research Publications, 3, 1-7.

Parimalam, P., Balakamakshi, K., \& Ganguli, A. K. (2006). Musculoskeletal problems of women bamboo workers in Madurai, India. Human Factors and Ergonomics Society of Australia Inc. Retrieved January 15, 2016 from www.ergonomics.org.au/.../HFESA2006_0016_paper_Parimalam.pdf

Pines, A., \& Aronson, E. (1981). Burnout: From tedium to personal growth. New York: Free.

Poleshuck, E. L. et al. (2009). Psychosocial stress and anxiety in musculoskeletal pain patients with and without depression. Gen Hosp Psychiatry, 31(2), 116-122. doi:10.1016/j.genhosppsych.2008.10.003.

Riabroi, W., \& Chaiklieng, S. (2011). Repetitive strain injuries among workers of the Stone sculpture industry, Chonburi Province. KKU Journal for Public Health Research, 4, 1-10.

Roizenblatt, S., Souza, A. L., Palombini, L., Godoy, L. M., Tufik, S., \& Bittencourt, L. R. A. (2015). Musculoskeletal pain as a marker of health quality: Finding from the epidemiological sleep study among the adult population of Sao Paulo city. Plos PNE, 10, e0142726. doi:10.137/journal.pone.0142726.

Salve, U. R. (2015). Prevalence of musculoskeletal discomfort among the workers engaged in jewelry manufacturing. Indian Journal of Occupational and Environmental Medicine, 19, 44-55. doi: 10.4103/0019-5278.157008.

Sanders, M. J. (2004). Ergonomics and the management of musculoskeletal disorders. Journal of Occupational Rehabilitation, 4, 329-333. doi: 10.1023/B:JOOR.0000047617.49637.39.

Shah, C., \& Vyas, N. J. (2015). Musculo-skeletal disorders (MSDs) risk assessment in traditional small scale industries by using REBA (rapid entire body assessment) method. International Journal of Science and Research, 4, 280-283.

Silva De, P. V., Hewage, C. G., \& Fonseka, P. (2009). Burnout: An emerging occupational health problem. Galle Medical Journal, 14, 52-55.

Sungkhabut, W., \& Chaiklieng, S. (2011). Musculoskeletal disorders among informal sector workers of hand-operated rebar bender: A pilot study. Srinagarind Medical Journal, 26, 225-232.

Stewart, W. F., Ricci, J. A., Chee, E., Morganstein, D., \& Lipton, R. (2003). Lost productive time and cost due to common pain conditions in the US workforce. JAMA, 290, 2443-2454. doi:10.1001/jama.290.18.2443 
Tangkittipaporn, J., \& Tangkittipaporn, N. (2006). Evidence-based investigation of safety management competencies, occupational risks and physical injuries in the Thai informal sector. Elsevier International Congress Series on Occupational Health, July, 39-41. Retrieved June 2, 2016 from http://www.ics-elsevier.com

Thanachaisethavut, B. (2011). Informal workers and legal protection in Thailand. WEIGO. Retrieved January 20, 2016 from http://www.wiego.org/sites/wiego.org/files/reports/files/T01.pdf

Thinkhamrop, W., \& Laohasiriwong, W. (2015). Factors associated with musculoskeletal disorders among registered nurses: Evidence from the Thai nurse cohort study. Kathmandu University Medical Journal, 13, 238-243.

Tops, M., Boksem, M. A., Wijers, A. A., Duinen, H., Den Boer, J. A., Meijman, T. F., \& Korf, J. (2007). The psychobiology of burnout: Are there two different syndromes? Neuropsychobiology, 55, 143-50. doi: 10.1159/000106056.

Tsarali, M., Papaliagkas, V., Damigos, D., Mavreas, V., Gouva, M., \& Tsolaki, M. (2014). Depression and anxiety levels increase chronic musculoskeletal pain in patients with Alzheimer's disease. Current Alzheimer Research, 11, 574-579.

Yoopat, P., Toicharoen, P., \& Glinsukon, T. (2002). Ergonomics in practice: Physical workload and heat stress in Thailand. International Journal of Occupational Safety and Ergonomics, 8(1), 83-93. doi:10.1080/10803548.2002.11076516

Yue, P. G., Xu, G., Li, L., \& Wang, S. (2014). Prevalence of musculoskeletal symptoms in relation to psychosocial factors. Occupational Medicine, 64, 211-216. doi: 10.1093/occmed/kqu008. 